\title{
The Meaning of Place in Supporting Sociality
}

\author{
Ann Light, Kate Howland \\ University of Sussex, UK \\ \{Ann.Light; \\ K.L.Howland\}@sussex.ac.uk
}

\author{
Tom Hamilton \\ University of Sussex \\ Falmer, UK \\ tom@tom-hamilton.co.uk
}

\author{
David A Harley \\ University of Brighton \\ Brighton, UK \\ D.A.Harley@brighton.ac.uk
}

\begin{abstract}
While social isolation in an ageing population is a concern in many locations, it is greater in towns where divisive local geography and declining investment conspire against meeting places and mutual awareness. This research into the design of location-based tools to support sociality asks whether embedded digital tools that make neighbourhood activities and/or people's movements more visible have the potential to increase serendipitous encounters and deepen a sense of community cohesion. Taking to the streets of a small town to explore if digital tools might improve the situation, we used participatory and provocation methods to inspire engagement with the theme and compare design concepts for sociality. Participants showed great passion for the town and its people, but also caution about publicly revealing even basic information, because of anticipated local consequences. They preferred an indirect approach. We use these insights to analyze "place" and discuss the specifics of designing for sociality in challenging contexts.
\end{abstract}

\section{Author Keywords}

Sociality; location-based services; privacy; ticket to talk; community; ageing; aging; place, third age.

\section{ACM Classification Keywords}

H.5.m. Information interfaces and presentation (e.g., HCI): Miscellaneous.

\section{INTRODUCTION}

Not everyone finds themselves growing old in the place of their dreams. Social isolation in an ageing population is of concern [1], especially where social and economic decline has impoverished local opportunity to meet others. Difficult socio-economic conditions create problems for residents, regardless of their own financial situation. Retired people on low incomes suffer particularly as they spend much of their day in their neighbourhood [27], but these conditions impact everyone. Within HCI, there is increasing effort to design tools to support people to lead full lives in their local environment. We build on this work to explore improving

\footnotetext{
Permission to make digital or hard copies of all or part of this work for personal or classroom use is granted without fee provided that copies are not made or distributed for profit or commercial advantage and that copies bear this notice and the full citation on the first page. Copyrights for components of this work owned by others than the author(s) must be honored. Abstracting with credit is permitted. To copy otherwise, or republish, to post on servers or to redistribute to lists, requires prior specific permission and/or a fee. Request permissions from Permissions@acm.org.

DIS 2017, June 10-14, 2017, Edinburgh, United Kingdom

Copyright is held by the owner/author(s).

Publication rights licensed to ACM. ACM 978-1-4503-4922$2 / 17 / 06 \$ 15.00$
}

DOI: http://dx.doi.org/10.1145/3064663.3064728 sociality where decline is impacting quality of life through fragmentation, alienation and crime. Our study takes as example an English harbour town ("Harborton"), which shares issues with many other towns, such as loss of industry and a breakdown in (a feeling of) mutual care.

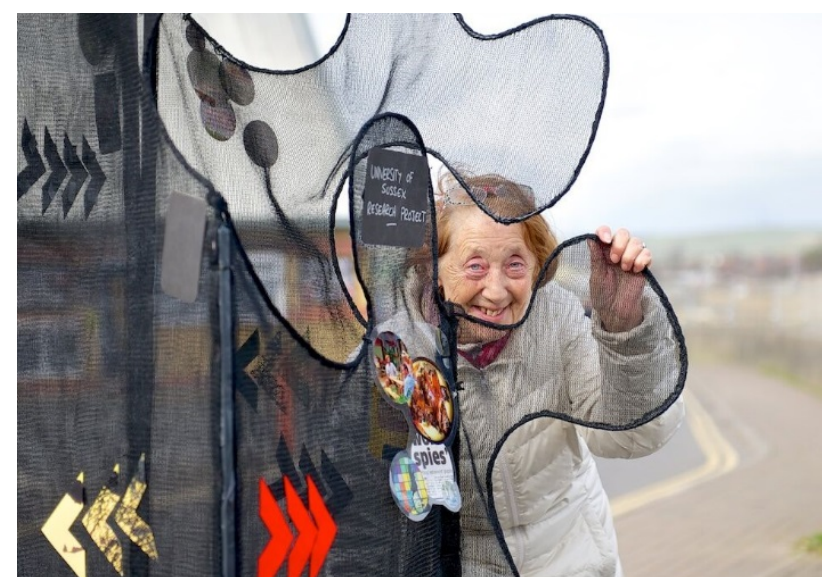

Fig 1. Participant and installation (C Ray Gibson)

Amid growing interest in potential for Internet of Things technology to augment public buildings and street furniture digitally, we chose to explore how embedded digital tools could support sociality. We used lo-fi design concepts on a street installation as provocation to ask local residents about sociality in a place where the challenges differ starkly from the tourist and cultural sites that attract much research on embedded media and location-based services. We note an early insight into located media that people are 'fascinated with the idea of knowing about people, places, and activities in the space immediately surrounding them' [37:288]. Paay and Kjeldskov [37] spoke to cosmopolitan young people in the vibrant capital city of Melbourne. How would findings differ for an economically-challenged small English town and its ageing population?

Based on an explorative study analyzing data gathered in a participatory design workshop and street interviews, we learnt that, despite interest in increased social connection in the neighbourhood, 1) people would not welcome tools that reveal individual movements; 2) disclosure of data is an everyday concern; 3) a balance between sociality and privacy can be achieved by providing indirect information about people's activities and whereabouts; 4) strong town identity can be used to support sociality.

Our contribution shows how tools of mutual awareness can help improve sociality, but only if designed to recognise 
local characteristics, reconcile different aspects of place and avoid adding to feelings of vulnerability. Taking older residents in an economically-deprived town as our sample, we reveal the acceptability of giving people indirect knowledge of others' activities. We consider Le Dantec and Edwards' suggestion that instead of 'simply challenging personal notions of public and private space, we could build technology that also challenges social notions of what it means to be connected or disconnected to each other' [28] and we close by considering our results in light of this.

\section{Local Geography and its Vulnerabilities}

We located the study in Harborton (pseudonym), being interested in how the impact of economic decline might be affecting sociality. Harborton is a UK coastal town at an estuary (population $\sim 12,000$ ). It used to have a major fishing industry and some high tech companies, but it has seen a decline in investment and economic prosperity. Although this downward trend was already in motion, there is consensus among Harborton residents that the decline took hold with development of a wide ring road to serve the port in the early 1970s. Running round the town centre, the road isolated the town's heart, cutting off key shops and services and walking routes and resulting in the loss of much commercial activity. Local government failure to counteract this attracted people trying to escape the high rents in other local areas, bringing both an artist community and people with challenging socio-economic issues. There are fewer than average people of working age living there, with disproportionate numbers of young children and thirdagers (those approaching retirement or retired but active).

Harborton is now an anomaly along the coast (where land costs are high) as an area of deprivation, empty shops and low employment. A negative spiral has been exacerbated by the removal of local statutory services, such as a dedicated police presence, while fragmentation of an already mixed population (built up by waves of immigration) has grown more pronounced. A series of commercial developments, imposed despite big local campaigns to stop them (such as siting an incinerator within the town), has further eroded any local sense of control. Many people feel ground down. We quote a comment from the study: 'If you want to know about the town just look at those three shops: the bookies [gambling], the funeral home [dying] and the bargain booze [drinking]. They're the only ones that are busy - they tell you everything you need to know about Harborton.'

Local residents may rightly feel that their streets are not as safe as others'. While fear of violence and actual violence do not correlate [10], crime statistics show that Harborton has more crimes per head per month than towns round it (www.crime-statistics.co.uk/postcode) and the crimes are different. Whereas nearby towns principally endure 'antisocial behaviour' and 'shop-lifting' with few crimes on the person, in Harborton, minor crimes are regularly exceeded by 'violence and sexual offences' (25-35 crimes reported per month) with some 'possession of weapons'.

\section{BACKGROUND}

We drew inspiration from studies about sociality, place and ageing in conducting this research, though found little work on location-based digital tools and older people.

\section{Place, Location and Tools}

The ICA Commission on Location Based Services (LBS) [26] asks how to enrich the abstract concept of "location" to reflect people's understanding of place, both individually and collectively, in LBS applications. Places have meaning for individuals and groups: 'Observing where other people are gathering and what they are doing there helps in getting an overview of a place, making sense of what is happening and sizing up the situation' [34: 287]. Discussing place underlines the nature of people-environment relations ([26], [24],[18],[11]), allowing us to speak more flexibly about location, beyond a particular building or spot.

Cranshaw et al [14] describe a tool that uses digital placemaking to affect physical locales, being 'motivated by the question of how location-based social computing can enhance the meaning, symbolization, and cultural relations experienced at physical non-places' [14: 4723]. Auge's [2] term non-place concerns environments that we do not invest with significance, such as places we travel through. By contrast, the work here is set somewhere where place turns out to be definitional, despite uncomfortable features.

A known concern with LBS is making people's location available to devices, raising disclosure issues, such as to whom knowledge is passed [19]. Much literature focuses on the dangers of revealing personal details (e.g. where you go or what you buy) to remote parties and how to protect your financial interests and be safe from undesirable surveillance [41]. Yet Consolvo and colleagues note that the findings of their study on revealing location to friends were 'quite different, for example, than giving one's home address to a business' [13], challenging this model. The privacy issues that arise with LBS have not been fully explored; we were interested to see if our interviewees had an opinion.

Overall, we asked how we could be sensitive to location (and any problems in it) when making something of value for third-age residents. Initiatives exist that address sociality and place when out and about (e.g.[3][35][34]), the take-up of public interactive opportunities (e.g.[5][48]) and locative media [47]. The work here brings these strands together, in the context of supporting an ageing demographic in a town where the challenges are different from those at the lively, cultural sites that attract most research.

\section{Sociality}

Protecting social aspects of one's life and keeping engaged in activities that feel meaningful are now known to be an important part of wellbeing (e.g.[30],[42]), especially as we get older. It is also noted that how we do this changes as we age ([9],[1]) as do emotional needs [15]. Insights such as these form the basis for much design for communal wellbeing and sense of community (e.g. [7],[43],[38]). Much of 
this ignores serendipitous sociality while out and about, focusing on people who are already known and expected.

Like babies and bad weather, dogs are an excuse for conversation with strangers. Sacks [40] described dogs as 'tickets to talk' for the people walking them. The concept of tickets to talk is picked up in designing for encounters with the very old by Blythe et al. [7], who site their study in a care facility. With our interest in ageing well round one's town and in one's familiar community, we return to Sacks' context of the street, noting the loss of places that people used to gather [25] and might meet serendipitously. Our study sought to learn about the types of mediation between people in a neighbourhood that an embedded, located tool might usefully supply, making a feature of 'place'.

The FLEX project, an inspiration for the work here, looked at participating in neighbourhood life as we get older [20], working in the British cities of Dundee and Newcastle to consider change communities can make to support engaged lives. It used a tea party to bring strangers over the age of 40 together to discuss 'living sociably as we age' [30], with an interest in how encounters can be both a research tool and research outcome for projects concerning sociality [30]. FLEX noted that thinking about maintaining sociability is a first step to a convivial old age as we get older, especially as venues such as corner shops and pension queues disappear [25]. It also observed barriers to casual meeting, such as awkwardness. It concluded that awareness of others and gentle prompts toward serendipitous meeting are needed both for personal wellbeing and for the overall health of communities.

A general trend over the last 20 years has been for places of sociality to move online [43]. The other project inspiring Material Traces explored older people's engagement with online forms of sociality (in an area of south England that includes Harborton). This suggested that email and Facebook are commonly used to maintain connection with distant family and friends [23]. The TraCE project sought to capture preferences of older people about local and online forms of community within the context of their everyday lives. It found that while many participants were open to meeting new people and making friends, this did not generally occur online. And, in this cohort, the most socially isolated in a local area were least likely to engage with online community. Online engagement was mostly found to reinforce local bonds and result in meetings. Faceto-face contact was seen as central to community; essential for exploring common ground with new people and for gauging their authenticity. Certain neighbourhood places (such as bus stops and doctors' surgeries) were deemed to be valuable for this and findings suggest potential benefits to embedding digital tools in key locations to further develop local community interactions [23].

When we looked at literature on users of embedded and location-based tools, we found older people did not feature in their own right; studies of older people socializing situate technology use at home (e.g. see [15], [46]). Typically, 'to date, LBS work with older adults has been grounded in a disability framework. In other words, researchers have focused on the benefits of LBS for older adults with dementia or with other cognitive or mobility deficits' [44]. Thomas et al [44] note this has not made services popular with their target of older British users (and see Vines et al. on HCI's negative perceptions of older people [45]).

In contrast to the more usual emphasis on the cognitive and physical elements of mature users' experience, including when mobile (e.g. [36]), we ask about emotional and social aspects of growing older in a particular place and moving through it, not to support physical or cognitive decline but to explore what technologies might enhance social aspects. These social features might not only benefit the Harborton residents who are retired or on the point of retiring, but, given the split demographic (young families and those in their 50s and above), we chose to focus on the needs and interests of the older group: the third-agers. While locationbased services (LBS) are in their infancy, embedded tools have the advantage that they do not require people to go online to use them, fiddle with small interfaces or manage complex interactions. Beyond such inclusive benefits, what kinds of service would appeal to mature residents?

\section{METHOD}

We chose an iterative research process, using participatory and provocation approaches and working with third-age participants. The study reported here starts with a workshop to inform design concepts for LBS in the town. We then took these concepts into the street to collect responses to the proposed functions of the designs prior to making decisions about appropriate digital interventions.

\section{Sample}

We wanted a sample of people to imagine different types of interaction in the streets of their town who could both inform on, and increasingly benefit from, tools for sociality. We wanted to talk to people thinking with the perspective of maturity, not youth; able to draw on memories of earlier days and compare. This made for a broad sample of thirdagers (e.g. [38]); not a precise demographic related to physical or cognitive attributes, but a social sample suited to the theme of community socializing. 'Third age is used to describe people who are either retired or approaching retirement age and remain broadly unaffected by health or mobility problems' [38]. It should be noted that we were not interested in 'old' people per se, but issues of ageing sociably, which is not associated with a tight age group (see Light et al [33] for a distinction). This also acknowledged the contingency of talking with those who come to a workshop or stop to chat in the street. If people looked 45 or more, we included them. Age was checked within a 10year band, but not at outset.

\section{Provocations}

The idea of provocation as a means for gathering responses to as-yet-undeveloped digital tools can be seen as 1) variant 
on lo-fi prototyping practices [1] to elicit reactions from potential users before any development work is undertaken; 2) as a probing method of gaining inspiration (e.g. [21],[8]), asking people to respond to an unexpected stimulus; and 3) as a trigger for raising social concerns with future designs ([1],[10]). As Boehner and colleagues [8] say: 'the designed application is itself thought of as a probe that forces new interaction, reflection, and reactions by users.' [8:1080]. In other words, its forebears set the street installation well within the 'critical artifact approach' [10]. We acknowledge all these motivations in taking a street installation into Harborton as a ticket to talk, yet also stress the locatedness of this choice and its use to act as exemplary of what it was intended to be - something that overrides social barriers to encourage conversation (evocative of the FLEX tea party).

Mounting lo-fi designs as an installation in Harborton's streets played up locational issues, as did running an initial workshop using maps to raise discussion of serendipitous encounters. The installation made it possible to conduct interviews at places where a social tool might be embedded (seafront, pedestrian area, park) and offer instantiation as to the forms it could take. The multiple designs incorporated in the installation allowed us to compare data both interinterviewee and between styles of design in any account (intra-interviewee). We used a semi-structured interview protocol to collect data: participants were encouraged to talk about what interested them in the installation, thereby eliminating order effects. Cited participants gave us permission to use their words and image in reporting.

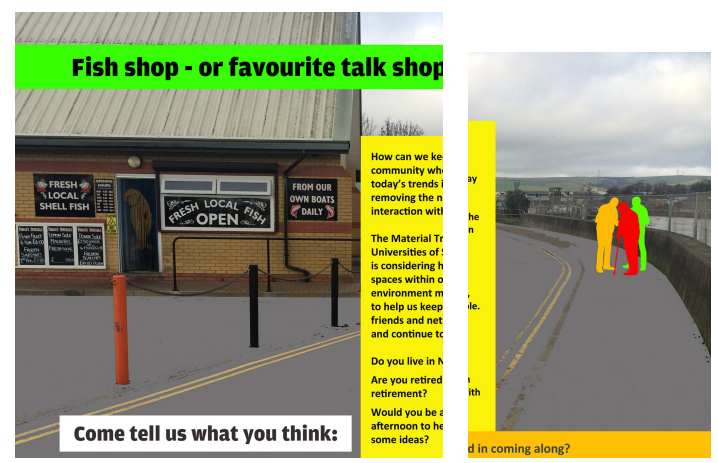

Fig 2. Sections of the (anonymised) poster for open workshop

\section{Preliminary Participatory Workshop}

In November 2015, an initial open workshop on residents' personal experience of sociality in Harborton was held at a local community centre in the town. The event was advertised through community networks and posters (Fig 2) and flyers were distributed through shops, social clubs and community centres. The tea-time workshop attracted six participants ( 2 men and 4 women), aged $45-85$ years. The event facilitator was the Material Traces researcher and all dialogue was audio-recorded for analysis.

The event employed Flex's tea-party method to draw out personal anecdotal experience of social life in the town. Tables for group work were set with creative prompts in the decoration of biscuits, crockery and tablecloths (Fig 3). Opening discussions explored conceptions of being social and identified categories of interaction. Participants were then invited to use these categories to map personal memories of important or unexpected interaction to the location where it occurred. The group considered how the characteristics of a particular location affect the nature of interactions there. And small groups also discussed how a location affects whom they want to interact with and how that might be mediated by a technological representation of some aspect of that person's presence or personality.

\section{WORKSHOP INSIGHTS}

It was noticeable that workshop participants, not all of whom knew each other, used the event to discuss issues facing the town. They told and/or showed us that:

- Harborton is made of a complex mix of populations and lacks a clear and single emotional centre. Despite this, there is a commonly shared memory of Harborton as a town with a higher than average sociability.

- There is a persisting desire for community and a safe, friendly town centre. There are community initiatives, however these exist in pockets around particular places and networks. One issue is the lack of visibility of community resources, while a second is their lack of availability (including, but not limited to, accessibility).

- There was some ambivalence and passivity expressed about the town's future compared to its history. Despite questions being couched in terms of increasing social interaction, there was a tendency for discussion to be framed in terms of community regeneration, with its implicit harking back to better times.

- A popular resource among these mature participants was the 'We love Harborton pictures' Facebook page (in which seascapes and sunsets play a prominent part).

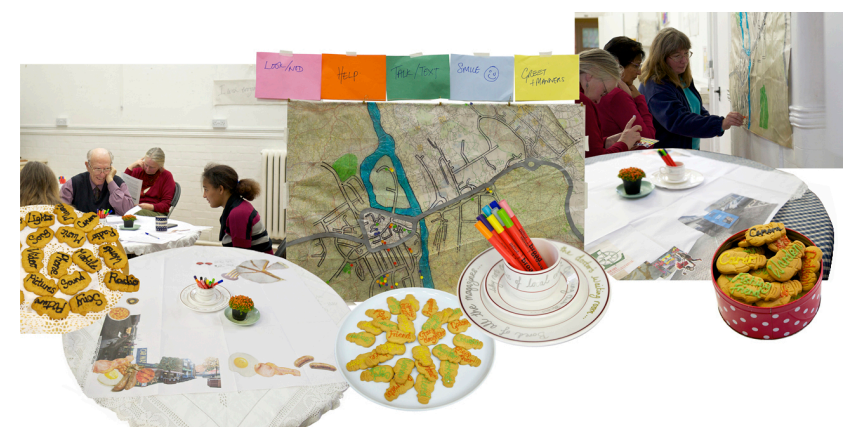

Fig 3. Generative prompts (ㄷ Ray Gibson)

It was evident that people desired something targeted at community. People said they wanted positive change, but could not unpack what community regeneration meant in terms of behavior or support for it. As can be seen above, much concern was about social connection and a safe town. We did not generalise any design decisions for the town from the group of six, especially as their views differed from those in the literature, but noted the keen discussion of socio-economic issues and lost community among local 
people meeting for the first time, as well as their priorities going forward. Participants were sceptical of external interventions, seeing them as a waste of money and telling stories of half-hearted social initiatives and local authority neglect. This too had to be considered in planning next steps - to establish if these issues were more general and what people's response to specific suggestions might be. To this end, we developed a ticket to talk to elicit more guidance. Supporting existing community initiatives was part of our original intention, but it was decided to adapt our study to explore more deeply why needs in Harborton might be different from those identified in previous studies, such as the findings from TraCE and FLEX.

\section{DEVELOPING THE TICKET TO TALK}

The 'material trace' to attract attention and act as our ticket to talk was to be a visually intriguing installation erected at a range of sites in the town. This would be a frame for four linked design concepts for discussion with passers-by. The four design concepts were drawn from workshop discussion and other inspiration that came from it, developed further by the design team and the researcher to make lo-fi prototypes of possible tools. The prototypes were used to elicit reactions inter- and intra-interviewee, so that we could see if one person preferred a particular type of encounter and whether this was true across the rest of our sample.

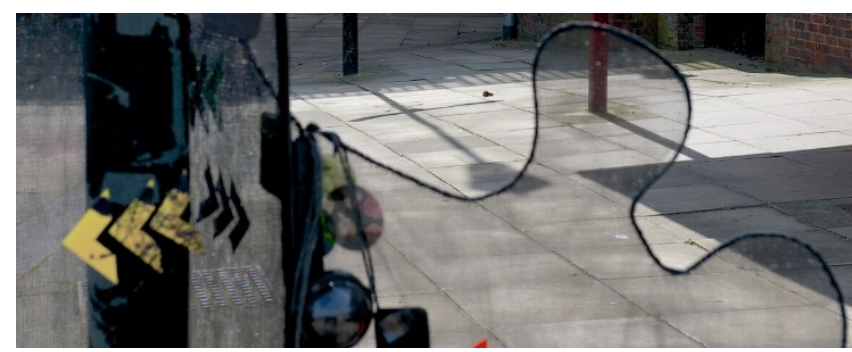

Fig. 4. Tidal Traces (C Ray Gibson)

\section{The Installation}

Our installation took inspiration from the coast: a folding screen frame shaped to resemble bladderwrack seaweed and covered in lightweight black nylon netting (Figs 1/3/4/10). This large flat form could be easily moved and reconfigured to fit with the range of proposed interview locations, with few health and safety issues. This frame formed a large neutral canvas for display of the four design concepts.

\section{Design Concept 1: Tidal Traces}

This design was most closely a trace. It used the idea of chevrons fading over time to represent residents (Fig 4/5), mapping social flow by indicating how recently a person had passed a particular place, their direction of travel and their speed. These traces would reflect the rhythms of key locations, and support the development of social relations. Identity would not be publicly available, but, like many other services, revealed by individuals to others within selected network groups, or intuited by observation of repeated collocation of an individual with a particular image. Considerations we hoped to elicit with this included privacy, security and the acceptability of sharing data.

\section{Design Concept 2: Thought Foam}

This design represented a variation of the first concept, created to arouse less concern through a higher level of innate anonymity. In this design, thought bubbles, in the form of randomised circles cut from an individual's most recently 'liked' or 'shared' webpages, would be captured as they passed through populous areas in the town. After a delay, individual bubbles (represented here by laminated circular images, Fig 5) would be added to a projected or screen-based display to make collective thought foam, stimulating social interaction by externalising town activity in interesting and unexpected juxtapositions.

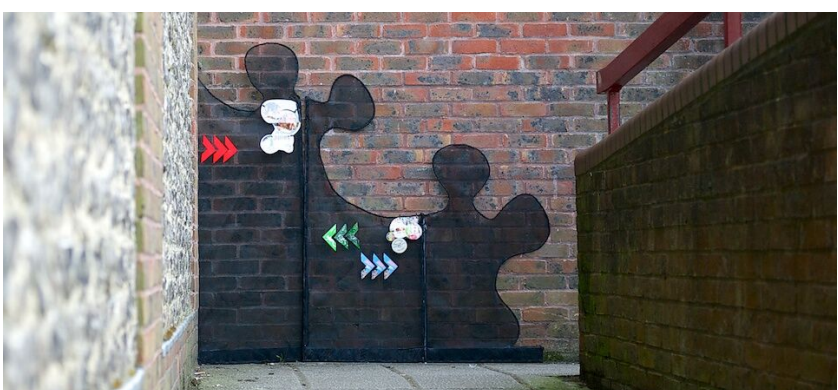

Fig. 5. Thought Foam and Tidal Traces ( Ray Gibson)

This concept drew on the workshop interest in collages of old photos of the town, the interest in social media pages dedicated to these photos and knowledge that Facebook is widely used (by older residents) in Harborton [23].

\section{Design Concept 3: Beachcomber Finds}

Workshop discussions included noticeboards, directories and community websites. Recognising the desire for a design that would reveal and build on the community initiatives already in the town, a third design offered a new way for people to encounter community news within public spaces and 'see into' unfamiliar networks and activities. Recreating the sense of serendipitous fun at finding something unexpected on the beach, the idea proposed small screens and projections (Fig 6).

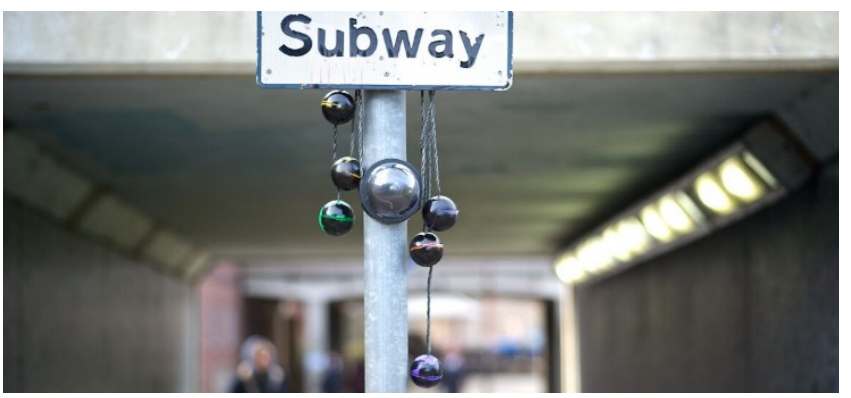

Fig. 6. Beachcomber Finds at the subway (C) Ray Gibson)

Although often dormant, these would occasionally display a piece of local information or live video feed to one of the community initiatives/centres (described as a 'window on the world' P7). From time to time, these might also display a voucher for a local shop, or code for a promotional offer to encourage people to check them each time they passed. The concept of Beachcomber Finds was therefore devised 
as a way to get people to look at their environment with fresh eyes and engage with local initiatives, such as the ' $W e$ Love Harborton Pictures' Facebook page.

\section{Design Concept 4: Message in a Barnacle}

The last lo-fi concept explored participants' desire for more physical forms of, and spaces for, interaction and a route for informal sharing. Physical notes/jokes/quotes could be left anonymously in a barnacle for someone else to find, whether by chance or prior agreement (Fig 7). This could be digitally augmented by allowing people to leave audio files or upload images via a USB port. The idea came from a local pub where notes can be left in tins nailed to the wall.

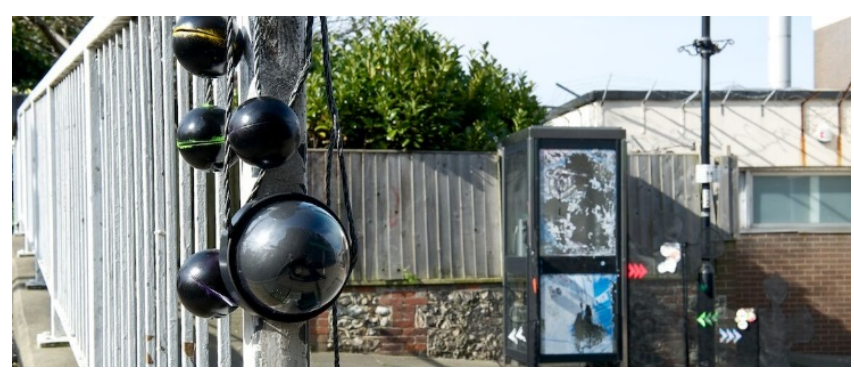

Fig. 7. Message in a Barnacle (ㄷ Ray Gibson)

\section{IN THE FIELD - METHOD OF ENGAGEMENT}

As detailed, we used a provocation to elicit responses. Because it was multi-faceted, we first explained our overall intent, then interviewed people about what jumped out at them, went into further detail and captured how they responded. Ten Harborton residents ( 7 men, 3 women) between 40-85 years old went on record being interviewed, all for an hour or more. We also heard, on the record, from a young woman (26) accompanying an older participant, which we include separately. We spoke to many more people in an informal capacity, which may have influenced the final analysis, but not in substantive ways.

\section{Siting the Study in Town}

Although we conducted interviews at a range of sites across the town (chosen for passing footfall, shelter, seating, visibility, ease of access, and health and safety issues), one site proved best: a quayside path next to a small park. We suggest this related to factors useful in thinking where an actual tool might be sited: there was a regular flow of people passing slowly enough that they did not feel on show in stopping to talk; their reason for being there was less errand-based than at other points in the town; and, when the sun was out, there was a pleasant space to sit and talk (Fig 8). By contrast, the subway area (Figs 4-6) was a reminder of Harborton's negative aspects, emphasising fragmentation and places where personal safety might be in question.

\section{Interviewing Style and Analysis}

The tone of the interviews was kept informal, with the researcher positioned as a member of an interested, but independent, design team, already aware of the impact of the town's history. Phrasing and style varied naturally with each interview. Although this resulted in a conversational, structure, care was taken in each individual interview to cover the questions in the semi-structured protocol: namely, which concept stood out, why, and, for each, if they would use it and what benefits and risks might attach to its use.

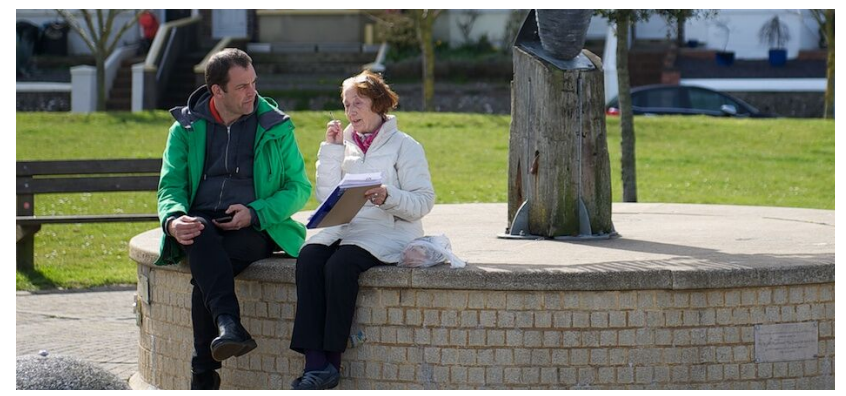

Fig 8. Talking in a quayside park (ㄷ Ray Gibson)

Interviews were audio-recorded and transcripts coded to identify repeating content, the $+/$ - valence of comments and emergent themes. First, all transcripts were read through to refamiliarize the interviewer with the content and establish a list of common topics and opinions. After this, transcripts were coded individually against this preliminary list - with any new themes or thematic distinctions being noted on the master list for inclusion in subsequent transcripts. Once all transcripts had been coded, the coding of each transcript was reviewed against the final master list. Two researchers independently assessed the collected material and clustered it by theme. Last, spatial and locational aspects of the accounts were examined, using discourse analysis [39].

\section{DESIGN INSIGHTS}

There were clear distinctions in responses to the design concepts. Based on the number and (researcher-attributed) valence of comments, we compare the four design ideas:

- Design 1, Tidal Traces, was widely discussed, (8 of 10 interviews), but all responses were neutral or negative.

- Design 2, Thought Foam, was also widely discussed, (in 9 interviews). Responses were very mixed, ranging from strongly positive to strongly negative.

- Design 3, the Beachcomber Finds, was most popular, attracting significant comment in all interviews and all responses being mildly to strongly positive.

- Design 4, the Message in a Barnacle, did not prompt much physical interaction and only 3 people shared opinions about it, from mildly positive to negative.

One overall finding was that everyone worried about the longevity of a system put into Harborton streets, stressing the need to make it vandal-proof. Another was that it was other people in the same locale provoking anxiety about privacy, not shadowy figures of government agencies, marketeers and phishers, watching from afar. Beyond that, there were many specific comments relating to each design.

Tidal Traces

Although the mechanism and purpose of a trace indicating where people have passed was easily understood, its value 
was questioned and concern was raised about misuse of the system, as well as issues of privacy and safety. Respondents were not convinced that seeing a friend's trace would encourage them to interact: 'It would be interesting to know if they had [been past]... I'd say, 'Oh yeah, Fred's been past' - but that's about as far as I [would go]' P8 (66-70 M). Similarly, in response to being asked if seeing the trace of a friend would encourage them to try to catch up: 'No...no...he 's probably doing his own thing, isn't he?' P9 (71-75 M). No one responded to the idea that they might begin to associate a frequent visible trace with a new person to talk to. Instead, it was dismissed as novelty and gimmick. 'Most people, I think, would pass it by-because they've got their own screen or they're not interested' P2 (71-75 F).

An area of agreement was the potential for the design to be used inappropriately to stalk or even harass individuals: ' $I$ think a lot of people would be suspicious. And it could be counter-productive - what if someone was stalked because of it?' P10 (56-60 M). For at least three of the participants, a factor was the perception that it would work especially badly in Harborton, e.g. 'It's a good idea, but it's the Harborton mentality. The Harborton way would be 'Oh, what a load of old crap' and 'I don 't want people following me when I go out, I don't wanna be followed...' That's the way we think.' P3 (55-60 M).

These findings suggest that representing people, even obscurely, would be the wrong approach. Our question as to how traces might mediate between private and public space was answered in the level of anxiety and number of negative comments about others. Although the idea was never to make both identity and location available to strangers at the same time, the very idea aroused concern about bringing on trouble in the neighbourhood.

A comment from the youngest interviewee (26), confirms that this is not just nervousness on the part of an older group of people: 'It could be used in the wrong way by the wrong people ...there are a small minority of people in this town - nosy, two-faced, back-stabbing little [X] - I wouldn't want to have them knowing where I'd gone or when, really, 'cos, we have enough issues without people going "Oh, look, they went there 10 minutes ago - oh, let's go give them aggravation". '

\section{Thought Foam}

The circles giving glimpses of what people are looking at took longer for participants to understand, but comments were positive, with no references to privacy or safety.

Some respondents suggested the playfulness of this design might capture people's attention - especially young people: 'Oh, kids would love that... That would go well over there in the sixth form college.' (P2); 'My generation would probably think 'What's all this about?', but the younger generation would pick it up. I think my [adult] son would absolutely love it.' (P3). Others were a little more cautious, but recognized that the design might stimulate spontaneous social interaction: 'Well, I've got my doubts. I don't know... on a bigger scale, maybe. And then people would get to know about it and come and, actually, do it on purpose.' P8. Participants could see that it might make them stop, look, and talk 'even to a stranger' (P8) and could provoke new patterns of behaviour: 'With a display system like that, people can contribute. They can go 'Here's a photograph of Harborton cliffs at low tide' and send it in. ' P4 (56-60 M).

However, this design also attracted some negative response, that it would be seen as a waste of money and too 'arty' i.e. the wrong approach to take in Harborton: 'I don't think that's going to fly in Harborton....I really don't - you're likely to get the bird [a rude gesture]... You know, no disrespect to the people that live in Harborton, but - that might work in [upscale area of London] or [local town with visibly different demographic], but I can't... I just can't see that flying - all you're going to get is: 'Well, that's taxpayers' money, mate.' (P10) and 'How much money you going to be spending on that? Because, well, doesn't really matter, but it won't be pennies.' P7 (56-60 M). In their eyes, while this might work better than a trace of individual people, the town as a whole would be skeptical. (Of course, many things engage the early adopters of a potential group before winning over others, so these responses do not mean it would fail to stimulate social interaction over time.)

\section{Beachcomber Finds}

Although the least conspicuous of the four designs, once the feature of occasional community news and event promotion was explained, this design elicited both the most discussion and the most positive support. 'So what you mean is that they'd have little monitors around the town which just told you what was going on, where you could go and direct you in the right position and the right times to go there. That'd be really good round this town.' P5 (40-45 M).

Many participants (as in the workshop) turned out to be keen to have more information on what is going on in the town - to plan ahead and as a reminder nearer the time. People commented that insufficient promotion of events means activities suffer from unnecessarily poor attendance, and that, though there are lots of events on, they only find out about them by accident. Things, such as the community garden, are known to be happening, but not where. And some mentioned being shy of getting involved, not knowing enough about the events to engage. Participants felt that part of the reason for this was that existing channels - local press, local radio and noticeboards - were not effective.

This information needed to be out in the environment: 'It is lack of exposure of this stuff to everyone - I mean, people that show an interest in social media, yes, they'll seek those things out, but the passerby - the average person going about their everyday business? So you've got to expose what's going on around Harborton to a wider group of people' (P4). One interviewee recalled previous initiatives designed at sharing local information, such as the member of the town council who 'got them to put pictures in the 
empty shops, when any of the shops downtown became empty... pictures of parts of Harborton ...he just felt that there were bagloads of wasted space when shops became empty.' (P2). This addressed both the information gap and the depressing effect of town-centre blight.

Digital screens were seen as a familiar tool that could be cheap and effective: '[The Post Office] has got rolling adverts - why don't we have something like that? Not in the Post Office; something actually in the town. It can't be expensive to have one in the café and the top of the town, one in the café in the middle of the town, so that people can see what's going on. Now, that would be a good idea. You're not encroaching on anyone's privacy and people don't even have to make the effort to open the computer up.' P10 (56-60 M). Interviewees noted there were business screens in use in the town but nothing for community events and that even a scrolling display in a shop window would be useful. Some also saw merit in interactive 'clickable' access to deep levels of information or live linkups to other parts of the town: 'I'm thinking of how on the bus these days you can see what's going on, the constant views of different [areas] - you could do that; different bits of Harborton showing different parts of Harborton.' (P7).

People came up with practical ideas when they considered this design, unlike their responses to other designs. It inspired them more. Yet, despite the generally positive response, there were again concerns around privacy and personal safety when people could be identified. The advocate for live link-ups (P7) considered his suggestion in the light of this vulnerability: 'I don't particularly trust the police, for instance. What sounds like a good idea could get transformed into being a spying mechanism. I think that would be people's fear. It turns out that people want to keep their lives private - and even though they're walking down the street, they think they're private.' (P7). And, as with all the design ideas, participants immediately commented that it would be prone to damage from anti-social elements within the community: 'Hmmm - that'd be nice. You'd have to make it vandal-proof.' (P10).

\section{The Barnacle}

Only three interviewees showed interest in the 'barnacles'. Once again, discussion revealed an underlying expectation about Harborton: 'It wouldn't work here, because you'd put that up and come back in two hours and that wouldn't be there; it'd be smashed to pieces. That is good for Harborton: two hours... even during the daytime. If you left that and you lot went away and come back, that'll be pulled down, that'll be on the floor and it'll be smashed... At nighttime, you'll be lucky if that'd be there in 10 minutes.' (P3).

\section{THE IDEA OF THE HARBORTON HAT}

As with the initial workshop (though the two groups did not overlap), the simple notion displaying public information about upcoming events, local networks and initiatives, and, potentially, live video feeds showing local projects found favour with street interview participants. This reinforced findings from the original workshop that what locals wanted most was to learn about neighbourhood activities in the town.

However, there was also support for a novel concept with a more personal flavour, developed during conversations in an early interview (P2) and then tried out with subsequent people. The idea, swiftly named the Harborton Hat, was for a head-mounted webcam that people wear at work (or school, etc.) so the feed could be shared as a first person point-of-view in monitors to give a sense of the everyday life of the town. This idea did not involve practical sharing of events or information, but of others' experience. This is close in spirit to the comment from P7: 'different bits of Harborton showing different parts of Harborton'.

This idea brought up privacy issues again, though opinion was mixed. For instance, P8 was personally unbothered, but anticipated others' concern: 'everyone's scared of each other now' (P8), while P10 also raised the issue, saying: 'They're a great idea - even if you were only going to wear it part of the time, because there are certain things you wouldn't want to share with the world wide web.' (P10). However, the participants that heard the idea (from P2 on) all found it appealing in showing local life yet without featuring the person him/herself.

\section{ANALYSIS OF PLACE}

In the interviews, we see a strength of opinion that, though the ideas might work elsewhere (such as nearby towns or London), few were appropriate for Harborton. Interviewees felt they live in a place at once harsher and more grounded: 'what Harborton would like is practical tools, they don't want quirky'. The message was that, not merely the speakers, but Harborton itself, did not want playful tools of engagement in its streets, because it is not that sort of town. Of course, this is not necessarily true (we spoke to a fraction of the 12,000 residents); rather the insight is the degree of projection about the town in people's comments about new tools for the town. They were not asked to speak for the town as a whole, but they often framed their answers in terms of what sort of town they perceived Harborton to be as they thought about located designs. And they had a ready and well-worn identity as residents of Harborton.

When this finding sent the team to look for this quality in other work it was evident that Harborton was talking about itself, with a set of concerns (loss of community, vandalism, being followed) and characteristics (practical, against waste of money) in a way that people in Dundee and Newcastle were not in the FLEX project [31], despite some similar issues being raised in the Dundee discussions (poverty, lack of safety). TraCE data, half of which was collected in Harborton (in people's homes rather than in public places), did not show many examples of speaking as/for the town. Individuals spoke about the importance of geographical location for building community, but there was not the prevalence of comments on distinctive characteristics of the towns in question or comparison with other places [23]. 
A potential influence is the siting of the conversation in the town, which is uncommon for in-depth interviews; another was the request to imagine using a street-based tool. In questions by the researcher, there was a frequent use of the word 'here' (e.g. 'Would this work here?'). While the term can mean 'this spot' (i.e. the wall on which we sit), it can also mean 'this area' (i.e. the defined geographic unit in which we sit) and it seems respondents often referred to the latter. In the data, we see people offer a view of Harborton spontaneously, as well as in answer to the researcher. Notably, people did not identify themselves by county, which would have been the next geographical unit up in scale. And they compared themselves with other local towns in a way that showed a strong and conflicted identity in thinking about new designs for the town.

\section{The Meaning of Place}

Another finding was the sheer number of ways that place informed the discourse of our interviewees. We have noted the difference between 'spot' and 'town'. We identified several further ways of understanding place, going beyond what we found in HCI and LBS literatures (though other literatures include their own, e.g. [29][16]). Taking the data, we produced a list of local interpretations:

- Place as spot - the immediate point, what is in view, how it varies between day and night.

- $\quad$ Place as site for encounter (or study interview) - what the environment provides for being here in more than passing, such as noise level, seats, shelter, etc.

- Place as community - how social patterns map to geographic boundaries, with overlapping territories.

- $\quad$ Place as town or village - with name and civic history.

- Place as source of pride - the emotional phantasm that maps to civic or other boundaries in people's minds.

- Place as absences, gaps and bits missing - the hidden, lost or unavailable parts that make it more than it is.

- Place as being of this town - seeing changes and contributing to them, history, hopes and ambivalence.

- $\quad$ Place as joy, threat or risk of exposure - the visceral comfort or discomfort of being here.

The list, itself, may be a useful addition to understandings of location and the layers of design possible and necessary for augmenting a town and its sociality through LBS.

\section{Placing the Tools}

There were also comments about siting the tools. Several people talked about placing screens round town and there was a suggestion that the blank walls of the leisure centre could be enlivened by using live screens as windows (P7), showing understanding of the potential of embedded media.

Unsurprisingly, there was a link between the content people wanted and places they hoped to see it. Old forms of media still held appeal: 'For us, something through the letterbox is what we'd really like... we could put it on our noticeboard and remember to go to it'. Many comments about providing information referred to its use in buildings (e.g. cafes or at home) as befits media to study or add to. Other suggestions were more in the spirit of the street: casual glimpses into others' lives, on foot, in passing, there to highlight events of the moment. 'Sticking bits of paper on walls, it's not the way to go. A tired, old-fashioned way; a lot of the posters are up so long. You can put up some nice big LED display screens showing what's happening in Harborton.' And there was mention of how much is missed 'It's hidden gems that get lost in Harborton - we need to connect more with our physical environment.' (P2). People did not respond specifically to the idea of content changing according to the person who approaches it, but there was a desire for wellchosen news and topical events relevant to the viewer.

\section{DISCUSSION}

We took a sample of people who could both inform on, and increasingly benefit from, tools for sociality and asked them to imagine different types of interaction in the streets of their town. This produced a rich discussion of the concepts in relation to the place (town/spot) in which they would be used, as well as people's individual likes and dislikes. The subtleties of their response show sensitivity to others, to their environment and to the characteristics of each design.

Le Dantec and Edwards suggest looking beyond personal boundaries to building technology that challenges social notions of what it means to be connected to each other [28]. We have begun to investigate what that might mean for one town with a history of community but a fragmented present.

\section{A 'Ticket to Talk' in a Hostile Environment?}

Our interviewees chose design concepts that do not directly expose themselves or others to encounters in their locale. Despite a strong interest in community and sociality, they chose to learn about things happening in the place they live, not about who is moving through it at a point in time. Given frequent allusions to the fractured environment and types of trouble that are part of their everyday life, this emerged as a strategy of gaining local intelligence while not becoming vulnerable. It is an understandable strategy - and not merely resistance to change - when it is looked at in the context of the menace that coexists with friendliness in the town. As noted, in Harborton, privacy involves protection from local people, not from those watching from afar.

If the environment does not feel safe, then issues of privacy and disclosure go beyond abstract concerns to personal jeopardy. Tools should allow people to pick their encounters and navigate safely, as well as socially. Having information about activity in the town gives some potential for interaction and a sense of connection, without giving out personal data. In this context, then, providing information about activity in the town promotes the town's sociality in that it both enables more people to attend events (thereby indirectly building community) and gives a prompt for discussion to anyone standing by the source. It is a ticket to talk mediated by town, not personal, information. Providing 'tickets to talk' about the town, not the individual resident, is no less an invitation to stop and chat than providing more 
personal information, but without the personal disclosure. It keeps information at a distance from individual persons (as well as from the personal in terms of data).

If we recall that many older Harborton residents principally see sociality in terms of meeting face-to-face [23], we can consider that disclosure may be viewed differently when getting together at an event or within a community group, where trust is higher, links are more apparent and expectations of fun are more likely to prevail.

It also points to the distinction between sociality in the moment and a sense of community cohesion, which can be enjoyed as a perception without actually talking to anyone, though the two may be closely related.

Even the Harborton Hat idea that people felt could proudly show Harborton scenes and locally show off town workers was conceived to leave the individual out of sight. But the Hat idea is interesting in another respect: it shows the town back to the town, allowing people to learn about each other. Conceived as serving the whole town, it may be most cohesive of the concepts. It is not utilitarian; there is no information offered in any practical sense. It builds insight, empathy and pride without direct social interaction. Perhaps this is to address Le Dantec and Edwards' [28] suggestion of a challenge to ideas of the social, showing that privacy concerns, pride and practicality can come together to create less intimate, but more culturally attuned, intervention. It suggests it could be interesting to include probes as to what counts as sociality in the actual design.

While the Hat is no more the 'solution' than the installation was, all the ideas tested in the street gave the research team useful insights and far more understanding of what would not be acceptable, as well as how to tune to local culture. This insight went far beyond that gathered in the workshop.

Is ageing significant in these findings? After all, our 26 year old responded much as the older interviewees. Ageing is relevant in thinking about why the tools might be needed. We are looking to support people to maintain and improve their social lives at a time when casual opportunities to meet, such as in pubs and pension queues, are diminishing. If you no longer have a place of work and rarely travel, immediate environments [32] must fulfill social as well as practical functions. These aspects make our findings more pertinent and poignant for older people, especially when, like our interviewees, they may be people who cannot take frequent or extended holidays as part of retirement and so escape town. The impact of age is as much emotional and circumstantial as related to the changes of advancing years. In choosing third-agers for whom retirement in Harborton is a reality or not far distant, we explored these circumstances.

Our informants had long memories: people recalled a different town of old and longed for a return to it. We heard the continuing hope they felt for a rebirth of this more social character. As in other studies (e.g. [21]), digital tools, such as phones and iPods, were associated with a loss of sociality, but more, the loss was seen as a failing of the town. Even if some of this is nostalgia, there is no denying that Harborton and many other towns and cities worldwide are struggling with diminished resources, less work and a sense of fragmentation, which current trends of social migration, austerity and automation aggravate. As climate change increases resource management issues, the need for means to cohere communities can only get greater.

\section{Tools for Sociality in Place}

The participants in this study do not need support. They are coping well with the adverse aspects of their circumstances and displaying the resilience that comes from being left to get by. But we think it important, nonetheless, to ask what can help them knit the social fabric of their town into better shape. We can ask: Do different technologies incorporate different notions of place? Can technologies address some notions of place and not others? The results of this study show that we do not need to detail the technical nature of located tools - how they input data, for instance - to gather a sense of their acceptability. We can stand in the street and get a feel for how their function works with the character of the place. But as we consider what types of intervention might improve residents' quality of life, we have to take the design of these relations very seriously. We have indicated the complexity of emotional understandings of place. When we bring in located tools, we intervene in many layers of engagement and change them. Our places can only become what we want them to be if we manage these layers of intervention in the designs we embed.

\section{CONCLUSION}

We asked people of the third age to consider designs for social encounters in their town, taking an installation into the street to provoke response. We addressed wellbeing as a neighbourhood phenomenon, which our design provocation supported well in terms of gathering nuanced data. People chose the least direct approaches to meeting others, mediated by activities of the town - seen through the eyes of local people or through finding others at events. This was not in opposition to digital tools located in the town; people were enthusiastic about any means possible to regenerate community. Our analysis of data revealed the significance of place, not only in terms of how desires differ between places, but as the mediator in finding a meaningful way to intervene in the sociality of this town. We suggest that many inner city areas - and other towns hit by decline might benefit from this approach, particularly where there is an ageing population. Our next step is to trial embedded tools to explore the impact of implementation.

\section{ACKNOWLEDGMENTS}

The AHRC for funding Flexible Dwellings for Extended Living (grant AH/J007153/1); the Leverhulme Trust for funding Light's International Academic Fellowship; and the Digital Economy's Communities and Culture Network+ for funding Material Traces and Trajectories to Community Engagement (EP/K003585/1). For any queries about reuse of our data sets, please contact the authors. 


\section{REFERENCES}

1. Age UK's Loneliness and Isolation Evidence Review, 2011, Age UK: URL

2. Marc Augé. 1992. Non-Places: An Introduction to Anthropology of Supermodernity, Le Seuil, Verso

3. Serkan Ayan and David Benyon. 2014. Designing blended spaces: historical echoes, testing a framework for digital tourism. Int. J. of Archetectonic, Spatial and Environmental Design, 7 (2). 1-12

4. James Auger and Jimmy Loizeau: http://www.augerloizeau.com

5. Ben Bengler and Nick Bryan-Kinns. 2015. I could play here for hours...(thinks the visitor and leaves): Why People Disengage from Public Interactives. In $A C M$ SIGCHI Conference on Creativity and Cognition (C\&C'15). 177-180

6. David Benyon, Phil Turner, Susan Turner. 2005. Designing Interactive Systems: People, Activities, Contexts, Technologies, Pearson Education.

7. Mark Blythe, Peter Wright, John Bowers, Andy Boucher, Nadine Jarvis, Phil Reynolds, Bill Gaver. 2010. Age and experience: ludic engagement in a residential care setting. DIS ' 10 .

8. Kirsten Boehner, Janet Vertesi, Phoebe Sengers and Paul Dourish, How HCI interprets the probes, CHI'07, April 28-May 03, 2007, San Jose, California, USA

9. Kim Boudiny. 2013. Active ageing: from empty rhetoric to effective policy tool, Ageing and Society 33(6), pp.1077-1098

10. Simon Bowen. 2009. Getting it Right: Lessons Learned in Applying a Critical Artefact Approach. In: Undisciplined! Design Research Society Conference 2008, Sheffield, UK, 16-19 July 2008

11. Ian Brunton-Smith, Jonathan Jackson, Alex Sutherland Bridging structure and perception on the neighbourhood ecology of beliefs and worries about violent crime, British Journal of Criminology, 2014

12. Luigina Ciolfi and Gabriela Avram. 2016. Digital Social Interactions in the City: Reflecting on locationbased social media, in Perng, S-Y and Kitchin, R. (Eds.), Code and the City, London: Routledge, 91-104

13. Sunny Consolvo, Ian E. Smith, Tara Matthews, Anthony LaMarca, Jason Tabert, Pauline Powledge Location disclosure to social relations: why, when, \& what people want to share, CHI'05, 2005

14. Justin Cranshaw, Andrés Monroy-Hernández and S. A. Needham, Journeys \& Notes: Designing Social Computing for Non-Places CHI'16, 2016, San Jose, California, USA.

15. Hilary Davis and Sonja Pedell, Older Adults' Use of a Novel Communication System: Client Goals versus Participant Experiences, $\mathrm{OzCHI} 2015$, 269-273
16. Guy Debord, Theory of the Dérive, Atlantic Books 1997

17. Adriana de Souza e Silva and Mimi Sheller (eds). 2014. Mobility and Locative Media: Mobile Communication in Hybrid Spaces, Routledge.

18. Paul Dourish. 2006. Re-Space-ing Place: Place and Space Ten Years On. CSCW'06 (Banff, Alberta), 299308.

19. Matt Duckham. 2012. Location Privacy. in Geographic Information Systems: Concepts, Methodologies, Tools, and Applications, USA Information Resources Management Association, 24-29

20. Flexible Dwellings for Extended Living: https://flexhousing.wordpress.com

21. Benjamin R. Garner. iPod use and the Perception of Social Introversion. Leisure Studies, 2014; 33 (1): 22

22. William Gaver, Tony Dunne and Elisa Pacenti. 1999. Cultural probes. interactions 6, 1 (Jan. 1999), 21-29

23. David. A. Harley, Kate Howland and Eric C. Harris. 2016. Trajectories to community engagement: Understanding older people's experiences of engagement with online and local communities. The Journal of Community Informatics, 12(1).

24. Steve Harrison and Paul Dourish. 1996. Re-place-ing Space: The Roles of Place and Space in Collaborative Systems. CSCW' '96. ACM, New York, NY, USA, 6776.

25. Paul Hickman. (2010) Neighbourhood Infrastructure, 'Third Places' and Patterns of Social Interaction, Centre for Regional Economic and Social Research Paper No. 4, Joseph Rowntree Trust, March 2010.

26. ICA Commission on Location-Based Services. 2016 LBS Research Agenda: Key Problems (Draft) http://lbs.icaci.org/lbs-research-agenda-a-first-list-ofkey-problems-and-the-vision-workshop-at-lbs-2016/ (retrieved 09.09.2016)

27. Ipsos MORI. 2015. Later life in 2015: an analysis of the views and experiences of people aged 50 and over. London, Centre for Ageing Better: http://www.ageingbetter.org.uk.

28. Christopher. A. Le Dantec and W. Keith. Edwards. 2008. Designs on Dignity: Perceptions of Technology Among the Homeless. In CHI '08, 627-636, 2008.

29. Henri Lefebvre. 1991. The production of space. Vol. 142. Oxford Blackwell.

30. Ann Light, Tuck W Leong and Toni Robertson. 2015. Ageing Well with CSCW. ECSCW'15: Springer. 295304.

31. Ann Light, Andrew Milligan, Lowri Bond, Linsey McIntosh and Carol Botten. 2013. High Tea at the Conviviality Café: Research Tool or Design 
Intervention?, Research Through Design Conference, Newcastle, Sept 2013

32. Ann Light, Clodagh Miskelly and Steve Thompson. 2008. An Analysis of Building Habitat with Networked Tools', Proc. OzCHI 2008, 180-187.

33. Ann Light, Sonja Pedell, Toni Robertson, Jenny Waycott, Jeanette Bell, Jeannette Durick and Tuck W Leong. 2016. What's special about aging. ACM interactions, 23 (2). 66-69.

34. Mark Marshall, Nick Dulake, Luigina Ciolfi and Daniella Petrelli. 2016. Using Tangible Smart Replicas as Controls for an Interactive Museum Exhibition, TEI 2016. New York: ACM, 159-167

35. David K. McGookin, Stephen A. Brewster and Georgi Christov. 2014. Studying digital graffiti as a locationbased social network, CHI'14, 3269-3278.

36. Emma Nicol, Mark D. Dunlop and Jutta Treviranus. 2016. Special Issue on Reimagining Interfaces for Older Adults - Guest Editorial Preface, IJMHCI 8(2) April-June-2016, ISSN: 1942-390X

37. Jeni Paay and Jesper Kjeldskov. 2008. Understanding Situated Social Interactions: A Case Study of Public Places in the City, J. Computer Supported Cooperative Work 17 (2-3) 275-290

38. Adam Park, Friederike Ziegler and Sarah Wigglesworth. 2016. Designing with Downsizers. University of Sheffield: http://www.housinglin.org.uk/_assets/DWELL_Design ingWithDownsizers.pdf

39. Jonathan Potter and Margaret Wetherell. 1987. Discourse and social psychology: beyond attitudes and behaviour. London Newbury Park, California: Sage.

40. Harvey Sacks.1995. Lectures on Conversation: Vol 1 \& 2. Oxford: Basil Blackwell.

41. Marcello Paolo Scipioni. 2012. A privacy-by-design approach to location sharing, Proceedings of the 2012 ACM Conference on Ubiquitous Computing, September 05-08, 2012, Pittsburgh, Pennsylvania

42. Geoff Shepherd, Jef Boardman \& Mike Slade. 2008. Making recovery a reality. London: Sainsbury Centre for Mental Health.

43. Charles Soukup. 2006 Computer-mediated communication as a virtual third place: building Oldenburg's great good places on the World Wide Web. New Media and Society, 8 (3), 421-440.

44. Lisa Thomas, Linda Little, Pam Briggs, Lynn McInnes, Emma Jones and James Nicholson. 2013. Location tracking: views from the older adult population, Age and Ageing.

45. John Vines, Gary Pritchard, Peter Wright, Patrick Olivier, Katie Brittain. 2015. An Age-Old Problem:
Examining the Discourses of Ageing in HCI and Strategies for Future Research, TOCHI, 22 (1), 1-27.

46. Joseph Wherton and David Prendergast. 2009. The Building Bridges Project: Involving Older Adults in the Design of a Communication Technology to Support Peer-to-Peer Social Engagement, in HCI and Usability for e-Inclusion, LNCS vol 5889, Springer, 111-134

47. Rowan Wilken and Gerard Goggin (eds). 2014. Locative Media. Routledge.

48. Johanna Ylipulli, Tiina Suopajärvi, Timo Ojala, Vassilis Kostakos and Hannu Kukka. 2014. Municipal WiFi and interactive displays: Appropriation of new technologies in public urban spaces. Technological Forecasting and Social Change 89, 145-160. 